\title{
Perkembangan Kewirausahaan Pada Mahasiswa Universitas Lancang Kuning Pekanbaru Berbasis Teknologi
}

\author{
Abrar Tanjung ${ }^{12}$ Ganefri ${ }^{1}$
}

DOI:

\begin{abstract}
Technopreneur one part of the development of entrepreneurship (entrepreneur) provides an overview of entrepreneurship by using technology-based innovation. The concept of technopreneur is based on a technology base that is used as an entrepreneurial tool, for example the emergence of an online application business and business security system. The purpose of this study is to conduct a descriptive study of entrepreneurship on students using technology (Technopreneurship) from all points of view, whether motivation, ownership, managerial, employment, and so on. technology as a basis for entrepreneurship. The results of the discussion found that the use of technology (Technopreneurship) in entrepreneurship can help and develop businesses in the form of product production and marketing of product results, so as to increase student income.
\end{abstract}

Keywords: technopreneur, entrepreneurship, students
1. Universitas Negeri Padang

2. Universitas Lancang Kuning Pekanbaru

EMail

abrartanjung77@gmail.com

Submitted: Desember 2019 Accepted : Juni 2020

\begin{abstract}
Abstrak
Technopreneur salah satu bagian dari perkembangan berwirausaha (entrepreneur) memberikan gambaran berwirausaha dengan menggunakan inovasi basis technologi. Konsep technopreneur didasarkan pada basis tekhnologi yang dijadikan sebagai alat berwirausaha, misalnya munculnya bisnis aplikasi online dan bisnis security system. Tujuan penelitian ini untuk melakukan kajian deskriptif tentang kewirausahaan pada mahasiswa dengan menggunakan teknologi (Technopreneurship) dari segala sudut pandang, baik motivasi, kepemilikan, manajerial, ketenagakerjaan, dan sebagainya technopreneurship bisa diedukasi melalui dunia pendidikan sebagai dunia transformas, yaitu ilmu mengembangkan kewirausahaan dengan menggunakan basis teknologi sebagai dasar berwirausaha. Hasil pembahasan di peroleh bahwa penggunaan teknologi (Technopreneurship) dalam kewirausahaan dapat membantu dan mengembangkan usaha dalam bentuk pembuatan hasil produk maupun dalam pemasaran hasil produk, sehingga dapat meningkatkan usaha dan pendapatan mahasiswa.
\end{abstract}

Kata Kunci: technopreneur, kewirausahaan, mahasiswa
JAS-PT

JURNAL ANALISIS SISTEM PENDIDIKAN TINGGI ISSN $2580-5339$ elSSN $2620-5718$

Volume 4

Nomor 1

JULI 2020

Hal 1-8

FORUM DOSEN INDONESIA 


\section{PENDAHULUAN}

Teknoprenuership merupakan pengembangan dari konsep kewirausahaan. Wirausaha adalah salah satu jawaban untuk menjawab ketimpangan antara pertumbuhan penduduk usia produktif dengan ketersediaan lapangan pekerjaan. Dunia pendidikan berkewajiban untuk dapat mencetak generasi - generasi yang memiliki kemandirian, termasuk kemandirian secara ekonomi. Sekolah, kampus juga media pendidikan informal lainnya bukan hanya berfungsi untuk berbagi ilmu dengan teori - teorinya maupun ketrampilan dengan praktek - prakteknya. Tetapi jika dikaitkan dengan masih rendahnya pemahaman dan minat tentang dunia wirausaha, dunia pendidikan dapat difungsikan juga sebagai media informasi untuk meningkatakan pemahaman dan minat anak didiknya pada dunia kewirausahaan. Untuk meningkatkan minat berwirausaha/entrepreneur salah satunya adalah dengan meningkatkan pemahaman dan minat masyarakat terhadap bidang wirausaha.

Menurut Tuker dan Senen 2009 bahwa kewirausahaan beberapa dekade terakhir telah menjadi perhatian bagi instansi pendidikan dan pembuat kebijakan, alasannya adalah karena dengan meningkatkan pertumbuhan pengusaha maka akan mendorong pengembangan ekonomi (melalui pengembangan ide usaha baru dan merubahnya menjadi suatu yang menguntungkan). Sedangkan McCleeland dalam Silvia mengemukakan bahwa suatu negara dapat maju apabila $2 \%$ dari total penduduk berprofesi sebagai entrepreneur. Kegiatan wirausaha harus didorong dengan keberanian dan keuletan serta tekad yang kuat, karena berwirausaha pada dasarnya berhimpitan dengan ketidakpastian, dalam hal keberhasilan maupun kegagalan. Karena hanya dengan menggeluti usaha secara penuh keberanian dan beresiko tinggi maka usaha akan tumbuh berkembang. Technopreneur salah satu bagian dari perkembangan berwirausaha (entrepreneur) memberikan gambaran berwirausaha dengan menggunakan inovasi basis technologi. Konsep technopreneur didasarkan pada basis tekhnologi yang dijadikan sebagai alat berwirausaha, misalnya munculnya bisnis aplikasi online, bisnis security system, dsb. Technopreneurship berasal dari gabungan kata "technology" dan "entrepreneurship" (Depositario, et al., 2011). Sosrowinarsidiono 2010 menyatakan bahwa Technopreneurship merupakan proses sinergi dari kemampuan yang kuat pada penguasaan teknologi serta pemahaman menyeluruh tentang konsep kewirausahaan.

Herwin 2015 menyatakan bahwa penciptaan wirausaha (entrepreneur) menjadi alternatif solusi atas berbagai masalah di masyarakat seperti kemiskinan dan kesenjangan sosial, meningkatnya pengangguran usia produktif dan menipisnya cadangan pasokan energi, yang kesemuanya menuntut adanya tindakan kreatif dan inovatif. Jiwa kewirausahaan bukan hanya sebatas kecerdasan akademik dan keterampilan menghasilkan produk tetapi juga jiwa dinamis dalam menangkap tantangan dan resiko kemudian mengubahnya menjadi peluang dan potensi pertumbuhan.

Universitas Lancang Kuning merupakan suatu lembaga yang berdiri pada tanggal 9 Juni 1982, mempunyai kegiatan dibidang pendidikan. Unilak merupakan sebuah

JAS-PT

JURNAL ANALISIS SISTEM PENDIDIKAN TINGGI ISSN $2580-5339$ eISSN $2620-5718$ Volume 4

Nomor 1

JULI 2020

Hal 1 - 8

FORUM DOSEN INDONESIA perguruan tinggi swasta yang mempunyai 9 fakultas pada bidang strata satu (S1) dan 2 program pascasrjana strata dua (S2). Mempunyai mahasiswa yang belajar di beberapa fakultas yang ada di Unilak berasal dari beberapa daerah yang ada di Propinsi Riau dan dari luar Propinsi riau bahkan ada yang berasal dari negara lain diluar Negara Indonesia, misalnya berasal dari Malaysia. Selain belajar kuliah mahasiswa juga di berikan kegiatan kewirausahaan di bawah lembaga Pusat pengembangan Karier dan Kewirausahaan (P2K2). Suatu lembaga berada di bawah Unilak yang menaungi 
kegiatan kewirausahaan dosen, karyawan dan mahasiswa. Kegiatan kewirausahaan di kelola dan di laksanakan oleh lembaga P2K2 dengan cara bentuk kegiatan sosialisasi dan praktek dan bekerjasama dengan beberapa lembaga di luar Unilak, misalnya karang taruna kelurahan di sekitar Unilak.

Tujuan penelitian ini untuk melakukan kajian deskriptif tentang kewirausahaan pada mahasiswa dengan menggunakan teknologi (Technopreneurship) dari segala sudut pandang, baik motivasi, kepemilikan, manajerial, ketenagakerjaan, dan sebagainya technopreneurship bisa diedukasi melalui dunia pendidikan sebagai dunia transformas, yaitu ilmu mengembangkan kewirausahaan dengan menggunakan basis teknologi sebagai dasar berwirausaha.

\section{METODOLOGI}

Leon et al 2007 menyatakan bahwa faktor-faktor yang memengaruhi Intensi Berwirausaha salah satunya yaitu Konteks Keluarga dimana menunjukkan adanya hubungan positif dan signifikan antara variabel konteks keluarga pada intensi berwirausaha. Partisipan yang menjadi sampel penelitian tersebut juga percaya bahwa kerabatnya (orangtua, saudara kandung, dan pasangannya) lebih mendorong mereka dalam mengejar karir sebagai wirasusahawan, namun kelompok referensi (reference group) seperti teman dan dosen sendiri justru sebaliknya. Faktor-faktor lainnya yang memengaruhi intensi berwirausaha adalah Entrepreneurial Skills. Berkaitan dengan konteks keluarga sebelumnya, bahwa berdasarkan hasil dari penelitian Hermina et al., 2011, kondisi peluang bisnis sangat mendukung minat untuk menjadi wirausaha. Dimana kondisi peluang bisnis dapat dikategorikan ke dalam faktor creativity dan mampu memperkirakan kebutuhan pasar (market awareness). Disamping itu menurut penelitian Silvia (2013) menghasilkan adanya pengaruh yang kuat antara kreativitas (creativity) dengan intensi kewirausahaan. Keberhasilan pembentukan jiwa entrepreneurial di kalangan kampus merupakan salah satu cara untuk memenuhi kebutuhan entrepreneur baru di Indonesia. Saat ini sejumlah perguruan tinggi telah memasukkan mata kuliah entrepreneurship sebagai mata kuliah wajib

Sudarsih dalam Prosiding KNIT RAMP-IPB (2013:57) mengemukakan bahwa technopreneurship adalah proses dan pembentukan usaha baru yang melibatkan teknologi sebagai basisnya dengan harapan bahwa penciptaan strategi dan inovasi yang tepat kelak bisa menempatkan teknologi sebagai salah satu faktor untuk pengembangan ekonomi nasional. Okorie 2014 menyebutkan bahwa technopreneurship adalah proses dalam sebuah organisasi yang mengutamakan inovasi dan secara terus menerus menemukan problem utama organisasi, memecahkan permasalahannya, dan mengimplementasikan cara-cara pemecahan masalah dalam rangka meningkatakan daya saing di pasar global. Dari pandanganpandangan diatas maka technopreneurship pada intinya akan menggabungkan antara teknologi dan kewirausahaan. Asri 2005 menyebutkan bahwa kewirausahaaan adalah kemampuan seseorang untuk mendirikan, mengelola, dan mengembangkan perusahaan miliknya. Kewirausahaan adalah tanggapan terhadap peluang usaha yang dilakukan dengan seperangkat tindakan yang menghasilkan organisasi yang melembaga, produktif, kreatif dan inovatif. Entrepreneur adalah orang yang membuat sesuatu yang berguna bagi sistem perekonomian dengan memperkenalkan barang dan jasa yang baru, menciptakan bentuk organisasi baru.

Mahasiswa yang berhasil memiliki usaha sendiri tergolong memiliki minat yang sangat kuat yang ditunjukkan dari sikap mereka selalu antusias untuk belajar tentang hal baru di dunia usaha dan selalu siap untuk membukabisnis baru. Bahwa minat dipengaruhi

JAS-PT

JURNAL ANALISIS SISTEM PENDIDIKAN TINGGI ISSN $2580-5339$ eISSN $2620-5718$ Volume 4 Nomor 1 JULI 2020 Hal $1-8$

FORUM DOSEN INDONESIA 
secara positif oleh sikap berperilaku, artinya bahwa semakin kuat (positif) penilaian individu terhadap baik tidaknya dampak menjadi wirausaha akan memperkuat keinginan individu tersebut untuk bekerja mandiri (self-employed) atau menjalankan usahanya sendiri. Dalam hal ini, semakin kuat sikap terhadap wirausaha, maka semakin kuat pula minat untuk menjadi wirausaha. Jackson dan Rodkey (1994) dalam Akmaliah dan Hisyamuddin (2009). Bisnis Plan adalah dokumen tertulis yang disiapkan oleh wirausaha yang menggambarkan semua unsur-unsur yang relevan baik internal maupun eksternal mengenai perusahaan untuk memulai usaha baru. Isinya sering merupakan perencanaan terpadu menyangkut pemasaran, permodalan, manufaktur dan sumber daya manusia. (Peters dalam alma, 2017).

Menurut Zimmerer (dalam Suryana,2001), mengemukakan beberapa faktor-faktor yang menyebabkan wirausaha gagal dalam menjalankan usaha barunya yaitu :

a. tidak kompeten dalam manajerial.

b. kurang berpengalaman

c. kurang dapat mengendalikan keuangan.

d. gagal dalam perencanaan.

e. lokasi yang kurang memadai. ;

f. kurangnya pengawasan peralatan.

g. sikap yang kurang sungguh-sungguh dalam berusaha.

h. ketidakmampuan dalam melakukan peralihan/transisi kewirausahaan

\section{HASIL DAN PEMBAHASAN}

Ono dalam Estiningsih dan Zaenal (2014) mentakan bahwa Entrepreneurship adalah proses mengorganisasi dan mengelola risiko untuk sebuah bisnis baru. Seorang entrepreneur melakukan hal-hal sebagai berikut :

a. Mengidentifikasi dan mengevaluasi peluang pasar.

b. Menemukan solusi-solusi untuk mengisi peluang pasar tersebut.

c. Memperoleh sumberdaya yang diperlukan (uang, orang, dan peralatan) untuk menjalankan bisnis.

d. Mengelola sumberdaya dari tahap awal (start-up) ke fase bertahan (survival) dan fase pengembangan (ekspansi).

e. Mengelola risiko-risiko yang berhubungan dengan bisnisnya.

Teknologi merupakan cara atau metode untuk mengolah sesuatu agar terjadi efisiensi biaya dan waktu, sehingga dapat menghasilkan produk yang lebih berkualitas. Dasardasar penciptaan tekologi adalah: kebutuhan pasar, solusi atas permasalahan, aplikasi berbagai bidang keilmuan, perbaikan efektivitas dan efisiensi produksi, serta modernisasi. Terdapat perbedaan antara entrepreneurship biasa dan technopreneurship (technology entrepreneurship). Technology entrepreneurship harus sukses pada dua tugas utama, yakni: menjamin bahwa teknologi berfungsi sesuai kebutuhan target pelanggan, dan teknologi tersebut dapat dijual dengan mendapatkan keuntungan (profit). Entrepreneurship biasa umumnya hanya berhubungan dengan

JAS-PT

JURNAL ANALISIS SISTEM PENDIDIKAN TINGG ISSN $2580-5339$ elSSN $2620-5718$

Volume 4

Nomor 1

JULI 2020

Hal $1-8$

FORUM DOSEN INDONESIA bagian yang kedua, yakni menjual dengan mendapatkan profit.

Pendidikan memiliki peran penting dalam pengembangan manusia seutuhnya dan pembangunan masyarakat Indonesia seluruhnya. Pengembangan manusia harus dilakukan secara utuh, yang mencakup pengembangan daya pikir, daya qolbu, daya fisik, dan penguasaan ilmu pengetahuan, teknologi, seni serta olahraga (Slamet, 2011). Selain itu, pengembangan manusia juga diharapkan menghasilkan manusia yang mampu dan sanggup berperan aktif dalam membangun masyarakat Indonesia 
seluruhnya. Technopreneur dan Pendidikan Pendidikan memiliki peran penting dalam pengembangan manusia seutuhnya dan pembangunan masyarakat Indonesia seluruhnya. Pengembangan manusia harus dilakukan secara utuh, yang mencakup pengembangan daya pikir, daya qolbu, daya fisik, dan penguasaan ilmu pengetahuan, teknologi, seni serta olahraga (Slamet, 2011). Selain itu, pengembangan manusia juga diharapkan menghasilkan manusia yang mampu dan sanggup berperan aktif dalam membangun masyarakat Indonesia seluruhnya.

Menurut Hendarwan, Pendidikan dan pelatihan kewirausahaan ini merupakan langkah serius dari pemerintah untuk mengatasi pengangguran terdidik yang terus bertambah jumlahnya. Ciputra (dalam Direktorat Kelembagaan Dikti, 2009) menegaskan bahwa pendidikan kewirausahaan bisa memberi dampak yang baik bagi masa depan Indonesia, seperti yang terjadi di Singapura. Namun kuncinya menurut Setiawan 2009, pendidikan harus dijalankan dengan kreatif. Sejalan dengan itu praktik kewirausahaan akan memberikan kontribusi moral dan material kepada pelaku usaha.

Putri menyatakan bahwa tugas sekor pendidikan baik formal maupun informal bukan hanya mencetak manusia - manusia yang berpendidikan, tetapi secara lebih luas lagi, sektor pendidikan harus mampu menciptakan manusia - manusia yang mandiri. Dengan kenyataan bahwa tidak semua penduduk Indonesia usia produkif dan tergolong sebagai angkatan kerja dapat terserap didunia kerja, maka sektor pendidikan bertanggungjawab untuk mencari solusi, bagaimana agar output yang dihasilkan tidak hanya berorientasi untuk menjadi pekerja, disisi peran sektor pendidikan untuk memperkenalkan dan memotivasi anak didiknya agar memahami bahwa selain menjadi seorang pekerja ternyata bidang wirausaha juga menjadi bidang yang cukup memjanjikan untuk didalami.

Kewirausahaan yang dilaksanakan mahasiswa berasal dari beberapa fakultas yang ada di Unilak, misalnya dari fakultas ekonomi, fakultas teknik dan fakultas ilmu keguruan dan pendidikan. Hasil kewirausahaan mahasiswa sudah banyak yang berhasil mencapai tingkat nasional, misalnya tingkat kopertis X (LLDIKTI X) bahkan sampai tingkat kopertis tingkat nasional. Namun dari hasil kewirausahaan mahaiswa masih belum banyak yang di kembangkan, karena kegiatan banyak di laksanakan secara manual bahkan pemasarannya juga secara manual. Selain dari kurangnya penggunaan teknologi, mahasiswa juga di sebabkan modal usaha yang diperoleh. Modal yang mahasiswa peroleh selama di peroleh dari biaya sendiri dan patungan dengan mahasiswa lainnya yang satu kelompok dengan mahasiswa. Sehingga menyebabkan usaha yang mereka lakukan kurang berkembang, hasil usha mereka kurang diketahui oleh masyarakat dalam dan luar kampus Unilak.

Sudah banyak yang dilakukan Universitas untuk memacu terciptanya Wirausahawan muda di kampus, namun sebagai inkubator bisnis masih belum optimal dalam hal Shared yakni belum menyediakan fasilitas kantor yang bisa digunakan secara bersama misalnya resepsionis, ruang konferensi, sistem telepon, faksimile, komputer, \& keamanan dan Synergy, yaitu belum tercipta kerjasama tenant atau persaingan antar tenant dan jejaring (network) dengan pihak universitas, lembaga riset, usaha swasta, professional maupun dengan masyarakat internasional. Secara umum, ada dua jenis bisnis yang dapat membentuk technology entrepreneur (technopreneur), yakni: bisnis lifestyle dan bisnis pertumbuhan tinggi (high growth businesses). Bisnis lifestyle adalah suatu usaha yang umumnya tidak tumbuh dengan cepat. Bisnis seperti ini biasanya tidak menarik bagi investor profesional seperti angel investor atau pemodal ventura (venture capitalist). Bisnis tersebut tidak mempunyai potensi yang cukup untuk

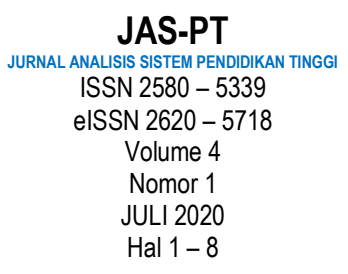

FORUM DOSEN INDONESIA 
menghasilkan kekayaan yang signifikan. Seseorang mungkin ingin menjadi bos sendiri, mengatur jadwal sendiri, dan ingin memiliki kendali yang lebih besar.

Penggunaan teknologi dalam kewirausahaan dapat di gunakan dengan cara menggunakan fasilitas internet, misalnya secara online memasarkan produk atrau hasil usaha mahasiswa khusus di dalam kampus Unilak, sehingga di ketahui oleh warga masyarakat kampus seperti dosen, karyawan dan mahasiswa lainnya. Selain dari pemasaran dengan cara on line, mahasiswa juga dapat dengan menggunakan teknologi, misalnya menggunakan aplikasi komputer dengan membuat program komputer yang bias bekerjasama dengan dosen yang membidangi komputer dan ekonomi. Dengan penggunakan teknologi baik dalam pelaksanaan produksi maupun pemasaran akan dapat meningkatkan dan mengembangkan hasil usaha mahasiswa. Sehingga dapat menambah penghasilan mahasiswa untuk membantu biaya kuliah. Salah satu penggunaan teknologi dalam pembuatan produk dan pemasaran produk hasil kewirausahaan sudah tersedia dalam bentuk pemasaran online dengan nama CA Entrepreneurship yang berada di lingkungan Unilak. Dalam nama ini hasil produk dan pemasaran mahasiswa sudah bisa di kirimkan dalam bentuk online shop. Selain mahasiswa juga bisa di gunakan oleh civitas akademika Unilak misalnya dosen dan karyawan. Pemesanan dapat menggunakan fasilitas online dan pengantaran hasil produk kewirausahaan bisa langsung di antar pada hari saat pemesanan atau dengan istilah one day one order.

\section{PENUTUP}

Simpulan yang dapat diambil dari hasil analisis data penelitian ini adalah

1. Program-program kewirausahaan yang telah digagas dan dijalankan oleh berbagai perguruan tinggi khususnya di Indonesia, patut kiranya dijadikan sebagai teladan dalam memulai memfokuskan perguruan tinggi dalam melahirkan entrepreneurentrepreneur muda sukses yang dapat pengintergrasikan konsep wirausaha dan konsep teknologi sehingga dapat meningkatkan potensi pengembangan usaha yang dimilikinya.

2. Program penumbuhan wirausaha baru harus dilakukan secara comprehensive dengan melibatkan seluruh pihak yang terkait baik pihak universitas, lembaga P2K2 maupun civitas akademika universitas, badan usaha dan lembaga-lembaga swadaya masyarakat. Semangat kebersamaan dan sinergi akademisi, dunia usaha, wirausaha baru dan segenap komponen masyarakat lainnya perlu terus menerus didorong agar lebih banyak mahasiwa yang menetapkan pilihan profesi menjadi wirausaha.

3. Penggunaan teknologi (Technopreneurship) dalam kewirausahaan dapat membantu dan mengembangkan usaha dalam bentuk pembuatan hasil produk maupun dalam pemasaran hasil produk, sehingga dapat meningkatkan usaha dan pendapatan mahasiswa.

JAS-PT

JURNAL ANALISIS SISTEM PENDIDIKAN TING

ISSN $2580-5339$

elSSN $2620-5718$

Volume 4

Nomor 1

JULI 2020

Hal $1-8$

FORUM DOSEN INDONESIA

\section{DAFTAR PUSTAKA}

Akmaliah, Z., dan H. Hisyamuddin, (2009),"Choice of Self-Employment Intentions Among Secondary School Studens", The Journal of International Social Research, Vol 2(9), pp.539-549

Asri Laksmi Riani. 2005. Dasar-dasar Kewirausahaan. Surakarta: UNS Press 
Clelland, David MC. (1961). Entrepreneur Behavior And Characteristics Of Entrepreneurs. The Achieving Society.

Estiningsih, Wening. Zainal, Arifin, HM, 2014, Technoprenuership; Challenge For Entrepreneurship Educational Development in Indonesia, Forum Tahunan Pengembangan Iptek dan Inovasi Nasional IV, LIPI, Tahun 2014

Hermina, U.N., Novieyana, S., dan Zain, D. 2011. Pengaruh Mata Kuliah Kewirausahaan Terhadap Minat Mahasiswa Menjadi Wirausaha. Jurnal Eksos, 7(2), pp: 130-141.

Herwin Moppanga, Studi Kasus Pengembangan Wirausaha Berbasis Tekhnologi (Technopreneurship) di Provinsi Gorontalo, Journal Trikonomika, Volume.14 no.1 TH. 2015

Leon, J.A., Descals, F.J., and Dominguez, J.F. 2007. The Psychosocial Profile Of The University Entrepreneur. Journal of Psychology in Spain, 11(1), pp: 72-84.

Mulyana, M. and Puspitasari, R., 2014. Model Struktural Minat Berwirausaha Siswa SMK Di Kota Bogor. SNIT 2014, 1(1), pp.83-91.

Mulyana, M. and Sulistiono, S., 2012. Kewirausahaan: The Long Life Way of Business.

Putri, Novita Delima, 2013, Pendidikan Kewirausahaan; Sebagai sebuah Tantangan Bagi Pengembangan Pendidikan Indonesia, Prossiding Seminar Nasional: Sustainable Competitive Advantages - 3. Unsoed, Purwokerto.

Slamet, PH (2011), Peran Pendidikan Vokasi Dalam Pembangunan Ekonomi, Cakrawala Pendidikan, Juni 2011, Th. XXX, No. 2.

Suryana. 2001. Kewirausahaan. Edisi Pertama. Jakarta: Salemba Empat.

Turker, D. and Senem S.S. 2009. Which Factors Affect Entrepreneurial Intention of University Students?. Journal of European Industrial Training, 3(2), pp: 142159. 
JAS-PT

JURNAL ANALISIS SISTEM PENDIDIKAN TINGGI

ISSN $2580-5339$

eISSN $2620-5718$

Volume 4

Nomor 1

JULI 2020

Hal 1-8

FORUM DOSEN INDONESIA 